\title{
Ultrasonic Couplants for Acoustic Microscopy of Low Speed Materials
}

\author{
Vahid Safavi Ardebili, Anthony N. Sinclair, Member, IEEE, and Jan K. Spelt
}

\begin{abstract}
A method is presented for estimating the compression wave velocities of organic fluids, based only on their density and molecular properties. The method is applied to a search for very low-speed ultrasonic couplants, suitable for $250 \mathrm{MHz}$ acoustic microscopy studies of epoxy materials. Experimental measurements confirmed that acoustic velocity could be predicted within $3 \%$ for simple fluorine-containing organic compounds, and within $10 \%$ for those with a more complex molecular structure. The compound 2-dichloropentafluoropropane $\left(\mathrm{C}_{3} \mathrm{HCl}_{2} \mathrm{~F}_{5}\right)$, with a compression wave velocity of $C_{L}=638 \mathrm{~m} / \mathrm{s}$ and acceptably low attenuation coefficient, was identified as a good coupling agent for acoustic microscopy studies of low speed materials.
\end{abstract}

\section{INTRODUCTION}

$\mathrm{T}$ HE HIGH resolution capability of acoustic microscopy makes it a suitable technique for depth profiling the mechanical properties of transition layers in sectioned specimens. A few attempts have been made to ultrasonically characterize the epoxy-adherend interfacial region in the cross section of an adhesive joint [1]. There is believed to be an epoxy "interphase" region of up to several microns thickness adjacent to the interface whose properties play a key role in environmental degradation of the bond [2]-[4]. Certain problems emerge in the application of commercial acoustic microscopy equipment to this task:

(1) A standard method of operation of an acoustic microscope is to subject the surface to a toneburst signal and evaluate the signal voltage, $V$, received back by the instrument as a function of the distance, $z$, to the surface. $V(z)$ normally displays an oscillatory pattern due to the interference of a specularly reflected longitudinal wave and an induced leaky Rayleigh wave (Fig. 1). In commercial acoustic microscopes, the objective lens is designed for water as the coupling agent, and the Rayleigh wave is excited by irradiating the surface with waves at a maximum incident angle, $\theta$, of approximately 50 degrees. From Snell's Law, however, it is not possible under such conditions to induce a Rayleigh wave in a low-speed medium such as epoxy, which has a shear wave speed of the order of $1100 \mathrm{~m} / \mathrm{s}$.

Manuscript received January 29, 1996; accepted July 12, 1996. Financial support for this project provided by the Natural Sciences and Engineering Research Council (NSERC) of Canada, and the MCHE of Iran.

V. S. Ardebili, A. N. Sinclair, and J. K. Spelt are with the Department of Mechanical Engineering, University of Toronto, Toronto, Ontario, Canada M5S 3G8 (e-mail: sinclair@me.utoronto.ca).
It is still possible to use sub-surface (lateral compression) waves in the study of such low-speed materials, but with two major drawbacks. First, lateral compression waves decay geometrically with depth, and would therefore be significantly affected by both surface and sub-surface material properties. By contrast, Rayleigh wave speeds are affected only by material properties up to depths of the order of 1 wavelength. Second, the major contrast mechanism in the imaging mode of the acoustic microscope is in Rayleigh wave interactions; it is therefore anticipated that Rayleigh waves offer the best prospect of providing good contrast in data collected on plastic specimens.

(2) Certain material surfaces can become measurably altered when exposed to the water couplant. The relatively small size of the water molecule and its chemical nature may lead to rapid water absorption. For some epoxy materials, the use of a couplant with molecules significantly larger than those of water may reduce the likelihood of surface contamination.

To address these challenges, it is necessary to identify an alternative coupling agent that has a large molecular structure, low acoustic velocity (longitudinal wave speed $C_{L} \simeq 800 \mathrm{~m} / \mathrm{s}$ ), and sufficiently low attenuation at frequencies up to several hundred megahertz to lead to acceptable signal-to-noise ratios. An enormous number of organic molecules, both natural and manufactured, satisfy the criterion of sufficiently large size to inhibit rapid absorption by an epoxy surface. However, the vast majority of these fluids have never been characterized with regards to their wave speed or attenuation coefficients, and it is not practical to measure individually the acoustic properties of them all. Unfortunately, there is currently no generally accepted method for a priori estimation of such properties based solely on the published chemical data for these fluids.

The objective of this work was to develop a method to rapidly identify possible candidates for a coupling agent to be used in the acoustic microscopy of epoxy adhesives at an operating frequency of $250 \mathrm{MHz}$. This list was then narrowed to two or three fluids that best met the requirements of low attenuation coefficient, low longitudinal velocity, acceptable boiling and melting points, commercial availability, and acceptable health and safety criteria.

There have been many theoretical and semi-empirical studies on correlations among physical, chemical, and electrical properties of molecules. Weissler [5] developed empirical relationships among the acoustic velocity $\left(c_{L}\right)$ of longitudinal waves, density $(\rho)$, refractive index, and molecular weight $(M)$ for a series of linear polymethyl- 


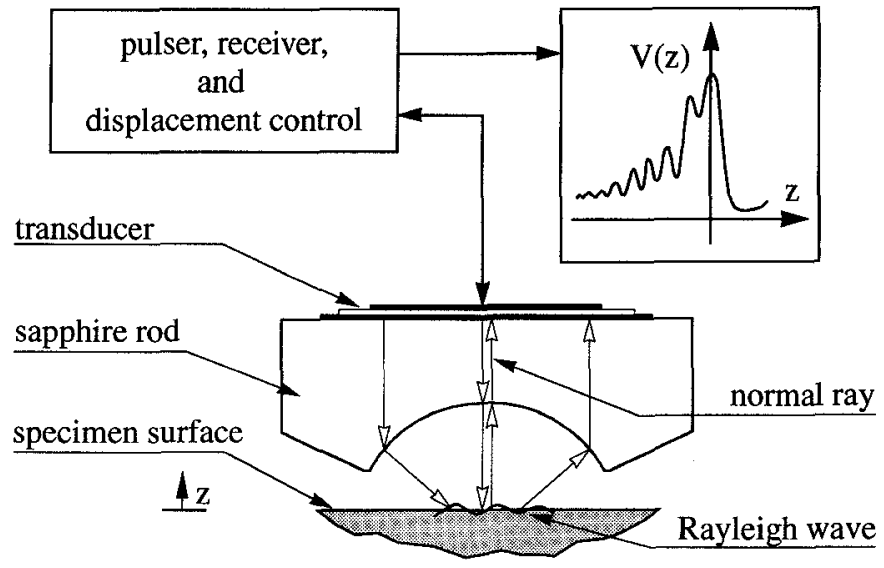

Fig. 1. Schematic of $V(z)$ measurement principle with acoustic microscope.

siloxane fluids; the work demonstrated that many siliconebased fluids have acoustic wave velocities in the general range required for the current work. Schaffs [6] sought a relationship between $c_{L}$ and molecular weight based on a van der Waal model of a liquid. The approach required the use of semi-empirical parameters whose values were dependent on the family of organic molecules under consideration. These parameters were evaluated for only a limited number of molecule types, none of which have velocities that are low enough for the current application. However, the excellent agreement that Schaffs obtained between predicted and measured acoustic velocities for a wide variety of organic fluids illustrated the power of the technique; this point was driven home by Sette [7] who demonstrated that Schaffs' semi-empirical formulas flowed naturally from theoretical models developed independently by Altenburg [8].

Attal and Quate [9], and later Briggs [10], proposed that a "coefficient of merit" be assigned to characterize a fluid's suitability as a high frequency ultrasonic couplant; good couplants were defined as those that had low attenuation, plus low acoustic velocity. These researchers were not interested in low velocity fluids from the standpoint of generating surface waves on plastics or adhesives; rather, they recognized that for a given frequency, the acoustic wavelength varies linearly with velocity, and short wavelengths correspond to a finer theoretical limit on the resolving power of the acoustic microscope. Although these researchers characterized several fluids with regards to their acoustic velocity and attenuation, none were suitable candidates for the present work, and no systematic method was proposed for a priori identification of fluids with the desired ultrasonic properties.

Briggs [10] suggested that methanol might be a suitable candidate to generate surface waves on slow materials, but its acoustic velocity is still too large for the current application. Knollman [1], following upon the measurements by Weissler [5], conducted ultrasonic work on adhesives using the silicone-based fluid Dow 200; however, the compression wave velocity of $870 \mathrm{~m} / \mathrm{s}$ is significantly higher than the ideal for acoustic microscopy studies of epoxy material.

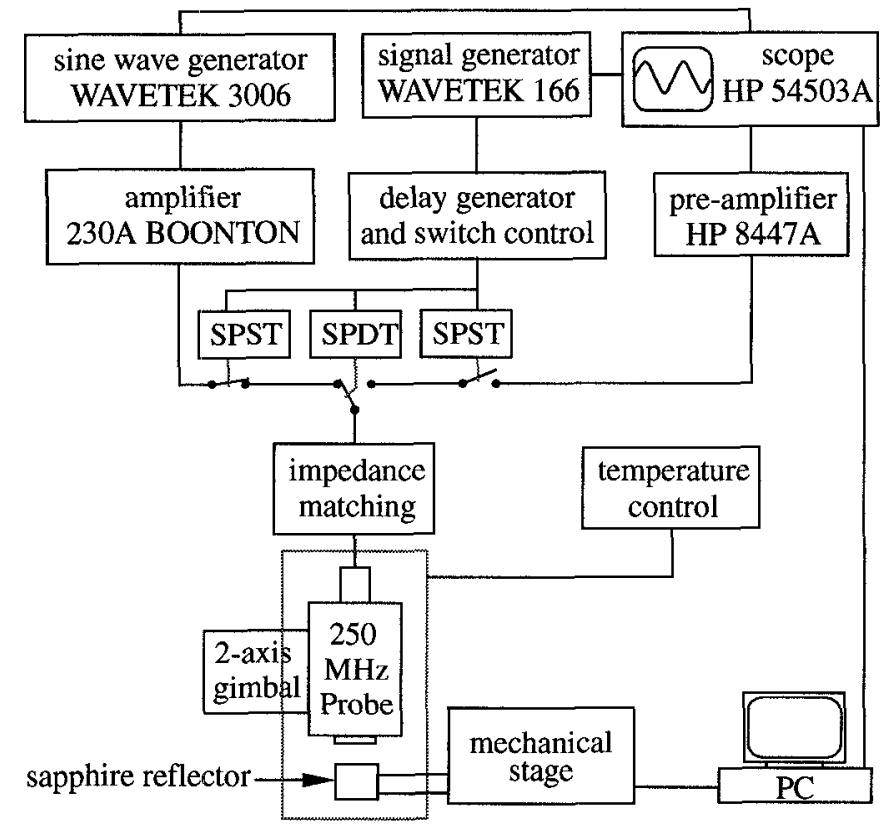

Fig. 2. Fluid speed and attenuation measurement setup.

Despite the many attempts and progress in correlating acoustic velocity to the molecular properties of fluids, there has been little parallel progress in numerical predictions of the ultrasonic attenuation coefficient, $\alpha$, for organic fluids. This is hardly surprising, considering the large number and complexity of attenuation mechanisms and the intricacy of large organic molecules. As theoretical estimates of attenuation coefficients will not be available to screen possible candidates for coupling agents, values of $\alpha$ must be measured individually, assuming that the list of candidates can be first reduced to a manageable size.

To limit the search to a reasonable size, the list of candidate couplants was confined to the fluorine-containing compounds with less than four carbon atoms; previous work by several researchers has indicated that this group may have members with relatively low values of $c_{L}$ and $\alpha$. This list was then narrowed by including only those fluids whose estimated acoustic velocities, based only on published chemical and physical data, are less than about 800 $\mathrm{m} / \mathrm{s}$. Those fluids satisfying additional minimum criteria regarding boiling point, melting point, health risk, and commercial availability, were evaluated further through ultrasonic tests.

\section{THEORY}

Schaffs' technique for predicting acoustic velocity is based on the assumption that the pressure, $p$, and molar volume, $V$, of a liquid can be related by a van der Waal equation. Following the notation of [7],

$$
\left[p+\frac{\rho^{2}}{M^{2}} a(T, \rho)\right]\left[\frac{M}{\rho}-b(T, \rho)\right]=R T
$$


TABLE I

Sample values of $A_{i}$ and $Q_{i}$ for estimating compression wave velocity by (4). Adapted from Schaffs [6].

\begin{tabular}{|c|c|c|c|}
\hline $\begin{array}{l}\text { Atom or atomic group, } \\
\text { and bond type }\end{array}$ & $\begin{array}{c}A_{i} \\
\left(\mathrm{~cm}^{3}\right) \\
\end{array}$ & $\begin{array}{c}Q_{i} \\
\left(\mathrm{~cm}^{3}\right) \\
\end{array}$ & $\begin{array}{l}\text { Sample molecule with } \\
\text { a bond of this type }\end{array}$ \\
\hline $\mathrm{H}-$ & 1.06 & & $\mathrm{C}_{3} \mathrm{HCl}_{5}$ \\
\hline$=\mathrm{C}<(1$ double bond \& 2 single bonds $)$ & 3.36 & & $\mathrm{C}_{3} \mathrm{H}_{3} \mathrm{BrF}_{2}$ \\
\hline$>\mathrm{C}<(4$ single bonds $)$ & 3.06 & & $\mathrm{C}_{3} \mathrm{HCl}_{7}$ \\
\hline$-\mathrm{C} \equiv(1$ triple bond $\&$ I single bond $)$ & 3.66 & & $\mathrm{C}_{3} \mathrm{H}_{2} \mathrm{Br}_{2}$ \\
\hline $\mathrm{Cl}(\mathrm{C})$ & 6.92 & & $\mathrm{C}_{3} \mathrm{HCl}_{7}$ \\
\hline $\mathrm{Br}(\mathrm{C})$ & 13.2 & & $\mathrm{C}_{3} \mathrm{Br}_{2} \mathrm{~F}_{6}$ \\
\hline $\mathrm{I}(\mathrm{C})$ & 16.0 & & $\mathrm{C}_{3} \mathrm{~F}_{7} \mathrm{I}$ \\
\hline $\mathrm{CH}_{3}(\mathrm{C})$ & & 0.10 & $\mathrm{C}_{3} \mathrm{H}_{3} \mathrm{I}$ \\
\hline $\mathrm{Cl}(\mathrm{C})$ (adjacent to $1 \mathrm{Cl}$ atom) & & 0.25 & $\mathrm{C}_{3} \mathrm{HCl}_{7}$ \\
\hline $\mathrm{Cl}(\mathrm{C})$ (adjacent to $2 \mathrm{Cl}$ atoms) & & 0.52 & $\mathrm{C}_{3} \mathrm{Cl}_{3} \mathrm{~F}_{5}$ \\
\hline $\mathrm{Cl}(\mathrm{C})$ (adjacent to $3 \mathrm{Cl}$ atoms) & & 0.75 & $\mathrm{C}_{3} \mathrm{Cl}_{6}$ \\
\hline $\mathrm{Cl}(\mathrm{C})$ (adjacent to 4 or more Cl atoms) & & 0.87 & $\mathrm{CCl}_{4}$ \\
\hline $\mathrm{Cl}(\mathrm{C})=(1$ single bond \& 1 double bond $)$ & & 0.87 & $\mathrm{C}_{3} \mathrm{Cl}_{2} \mathrm{~F}_{4}$ \\
\hline $\mathrm{Br}(\mathrm{C})$ (adjacent to $1 \mathrm{Br}$ atom) & & 4.2 & $\mathrm{C}_{3} \mathrm{Br}_{2} \mathrm{~F}_{6}$ \\
\hline $\mathrm{Br}(\mathrm{C})$ (adjacent to $2 \mathrm{Br}$ atoms) & & 4.5 & $\mathrm{C}_{3} \mathrm{H}_{4} \mathrm{Br}_{4}$ \\
\hline $\mathrm{Br}(\mathrm{C})$ (adjacent to 3 or more $\mathrm{Br}$ atoms) & & 6 & $\mathrm{C}_{3} \mathrm{H}_{5} \mathrm{Br}_{3}$ \\
\hline $\operatorname{Br}(\mathrm{C})=(1$ single bond $\& 1$ double bond $)$ & & 4.75 & $\mathrm{C}_{3} \mathrm{H}_{5} \mathrm{Br}$ \\
\hline $\mathrm{I}(\mathrm{C})$ & & 4.6 & $\mathrm{C}_{3} \mathrm{H}_{5} \mathrm{I}$ \\
\hline
\end{tabular}

where $R$ is a constant, $M$ the molecular weight, and a and $b$ are parameters dependent on temperature, $T$, and density, $\rho$. The co-volume term, $b$, is linearly related to the effective volume, $B$, occupied by 1 mole of molecules:

$$
B=\frac{b}{4}=\frac{4 \pi}{3} r_{m}^{3} N_{a}
$$

with $N_{a}$ equal to Avogadro's Number, and $r_{m}$ the molecular radius. Schaffs observed that for many organic compounds, the product $c_{L} V$ varies approximately linearly with $B$, if the $B$ value is determined from (2) by summing the relevant contributions from all constituent atoms, as

$$
B=\sum_{\text {all atoms } i} z_{i} A_{i}
$$

where $z_{i}$ is the number of atoms of type $i$ in the molecule and $A_{i}$ is an atomic constant. The relationship between $c_{L}$ and $B$ can then be expressed as

$$
c_{L}=W \frac{\rho B}{M}-\frac{W}{1+B / \beta},
$$

where $V=M / \rho$. The second term in (4) is much smaller than the first, and may be thought of as a correction to account for the presence of heavy atoms or atomic groups in the molecule. The proportionality constant $W$ has an approximate value of $4450 \mathrm{~m} / \mathrm{s}$. The parameter $\beta$ is determined by summing the contributions from the molecule's constituent atoms and atomic groups, each weighted by a parameter $Q_{i}$ :

$$
\beta=\sum_{\text {all atoms } i} z_{i} Q_{i}
$$

Values for the parameters $A_{i}$ and $Q_{i}$, as determined by Schaffs, are shown in Table I for several atoms and atomic groups commonly found in organic molecules. Unfortunately, these data do not include values for atoms of $\mathrm{Alu}$ orine, which are present in many of the compounds of interest.

\section{Procedure}

Initial estimates for the parameters $A_{i}$ and $Q_{i}$ for fluorine were made by extrapolating the Table I values for bromine, iodine, and chlorine as functions of molecular weight. These preliminary estimates were then refined as follows. First, three organic fluids containing fluorine were located for which published values of acoustic velocities were readily available: $C_{6} H_{5} F$ [11], $C_{8} H_{4} F_{6}$ [12], $C_{7} F_{16}$ [13]. The estimates of $A_{i}$ and $Q_{i}$ for fluorine were then refined to minimize the least squares difference between the published values of $c_{L}$ for these three fluids, and speeds calculated from (4). These steps, plus later refinements, led to estimates of $A_{i}=3.844 \mathrm{~cm}^{3}$ and $Q_{i}=1.815 \mathrm{~cm}^{3}$ for fluorine atoms bonded to carbon. These data were then added to Table I to allow a preliminary search for coupling fluids that would be candidates for acoustic microscopy studies of epoxy surfaces.

The compression wave velocities for over 200 halogencontaining fluids that have three or fewer carbon atoms were then estimated according to (4), using published data for the density of each fluid. From the list of $200 \mathrm{com}-$ pounds, those with estimated compression wave speeds of more than approximately $800 \mathrm{~m} / \mathrm{s}$, unsuitable boiling points, excessive toxicity, or commercial unavailability were eliminated from further investigation. This produced a list of nine candidate fluids, shown in Table II. For purposes of comparison, couplants suggested by other researchers for acoustic microscopy studies are also shown 


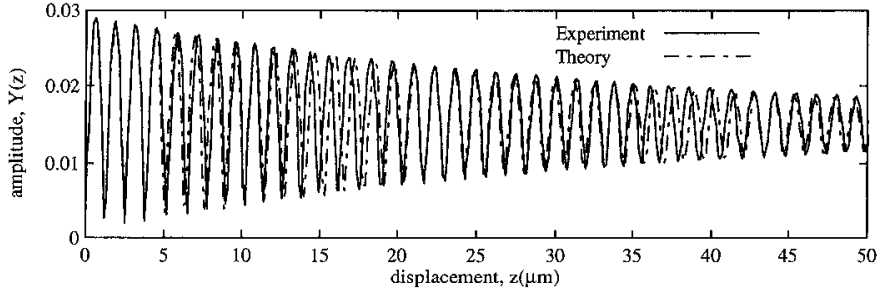

Fig. 3. Interference pattern obtained from ultrasonic measurements of 2-dichloropentafluoropropane at $250 \mathrm{MHz}$. Theoretical profiles was constructed through optimization of the parameters $X_{1} \ldots X_{6}$ of (6) through (8).

in Table II: water, methanol, ethyl-iodide, methyl-iodide, FC-72, and DOW-200.

The wave velocity and attenuation factor at $28.5^{\circ} \mathrm{C}$ were then measured for each of the fluids of Table II, using the apparatus shown in Fig. 2. The Wavetek 3006 generator produces a $250 \mathrm{MHz}$ continuous sine wave, with a frequency accuracy of $\pm 0.001 \%$. This wave is split in two: one part is chopped to produce a 500 ns toneburst and passed through isolation switches to a $250 \mathrm{MHz} \mathrm{ZnO}$ piezoelectric layer deposited on a sapphire rod. The transducer sends the ultrasonic signal through a small control volume containing approximately $0.1 \mathrm{ml}$ of the test fluid, maintained at $28.5^{\circ} \mathrm{C}, \pm 0.2^{\circ} \mathrm{C}$. The signal is bounced off a sapphire reflector immersed in the fluid, whose vertical position, $z$, is controlled by a mechanical stage with a nominal resolution of $0.013 \mu \mathrm{m}$, and an absolute accuracy of $\pm 1 \mu \mathrm{m}$. The reflected signal is passed back through the probe, impedance matching circuitry, and isolation switch to a pre-amplifier. This reflected signal is then automatically sampled by an oscilloscope for up to 1000 different values of $z$, spanning a total range of approximately $100 \mu \mathrm{m}$. These 1000 echo signals are then fed to a personal computer for analysis, together with the other half of the split sine wave coming directly from the generator. Timing for the sampling and switching operations is controlled by a WAVETEK 166 signal generator.

The sampled continuous sine wave has a circular frequency, $\omega$, corresponding to $250 \mathrm{MHz}$, and a constant amplitude assigned the symbol $X_{1}$. The ultrasonic echo signal is represented by $C_{1} \sin (\omega t+\phi)$, where the amplitude $C_{1}$ is a function of $z$, as

$$
C_{1}=\frac{X_{2} e^{-2 \alpha z}}{2\left(z+X_{3}\right)}
$$

In the numerator of (6), $X_{2}$ is a proportionality constant, and the exponential represents the attenuation relative to the position $z=0$ for the sapphire reflector. The denominator accounts for the approximate $1 / \mathrm{r}$ dependence of the beam divergence (diffraction) loss in the far-field of the transducer, where $X_{3}$ is the fluid-equivalent distance from the transducer to the reflector at $z=0$. Because the value of $z$ never exceeds about $100 \mu \mathrm{m}$, and $X_{3}$ is of the order of $50 \mathrm{~mm}$, the denominator of $(6)$ is essentially constant.
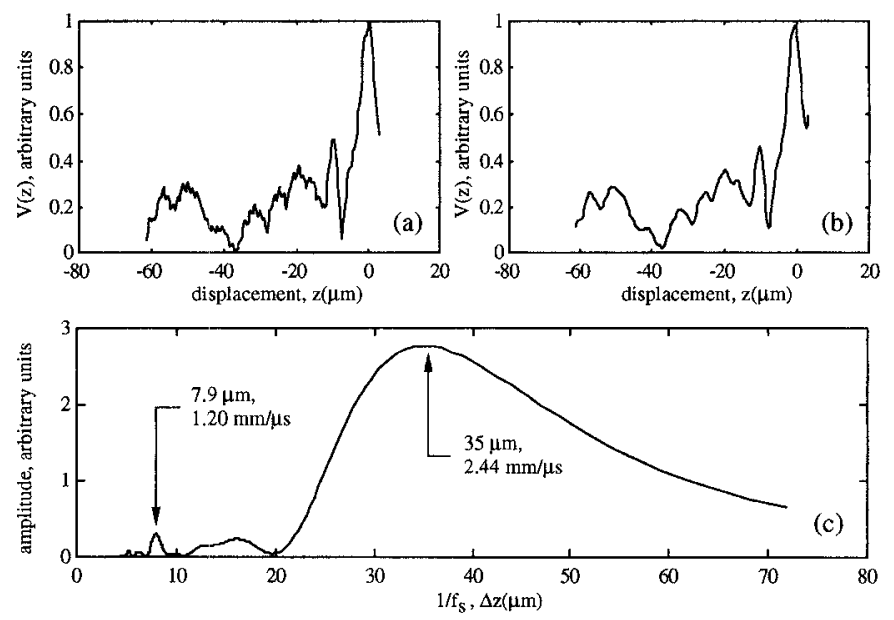

Fig. 4. (a) Experimentally recorded $V(z)$ on an epoxy specimen (HYSOL EA 9346). The measurement was performed at $250 \mathrm{MHZ}$ and the coupling fluid was 2-dichloropentafluoropropane. (b) The same $V(z)$ curve after removing the short period ripples by a software filter. (c) Spatial spectrum of a portion of Fig. 4(b) corresponding to the range $-62 \mu \mathrm{m}<z<-8 \mu \mathrm{m}$. The horizontal axis represents the inverse of spatial frequency $f_{s}$.

The phase, $\phi$, of the echo signal is also a function of $z$ :

$$
\phi=2 \pi \frac{\left(2 z-X_{4}\right)}{X_{5}},
$$

where the parameter $X_{4}$ is included as a reference point for the phase, and $X_{5}$ is the ultrasonic wavelength at $250 \mathrm{MHz}$. Through digital subtraction of the echo signal from the continuously sampled sine wave, an interference waveform is obtained with amplitude

$$
Y(z)=\sqrt{X_{1}^{2}+C_{1}^{2}-2 X_{1} C_{1} \cos \phi}
$$

Substituting expressions for $C_{1}$ and $\phi$ from (6) and (7) into (8), and assigning the parameter $X_{6}$ to the attenuation coefficient $\alpha$, yields an expression for $Y(z)$ for each fluid as a function of $X_{1}, \ldots, X_{6}$, and $z$. An optimization routine was then used to determine the best six values of the $X_{i}$ for each fluid, through comparison of (8) with the measured voltage levels $Y(z)$. The excellent fit between measured voltage levels and (8), after parameter optimization, is shown in Fig. 3 for the fluid 2-dichloropentafluoropropane.

This procedure was repeated for each of the fluids in the top portion of Table II, and the wave velocities were calculated by multiplying the wavelength $X_{5}$ by $250 \mathrm{MHz}$. Values of $c_{L}$ and attenuation coefficient, $\alpha$, obtained from these measurements are shown in Table II.

\section{Discussion}

From Table II, it is readily seen that (4) is a reliable indicator of the acoustic velocity for most of the fluids for which experimental measurements were made. As noted by Schaffs, the theoretical estimate for $c_{L}$ is most accurate for relatively simple molecules; discrepancies of the 
TABLE II

LONGITUDINAL WAVE VELOCITIES OF ACOUSTIC COUPLANTS FOR ULTRASONIC MICROSCOPY OF LOW SPEED MATERIALS.

\begin{tabular}{|c|c|c|c|c|c|}
\hline $\begin{array}{l}\text { Candidate fluorine-containing com- } \\
\text { pounds for acoustic microscopy }\end{array}$ & Formula & $\begin{array}{c}\text { Measured } \alpha \text { at } \\
250 \mathrm{MHz}(\mathrm{dB} / \mathrm{mm})\end{array}$ & $\begin{array}{l}\text { Theoretical } c_{L} \\
\text { from }(4)(\mathrm{m} / \mathrm{s})\end{array}$ & $\begin{array}{l}\text { Experimental } \\
c_{L}(\mathrm{~m} / \mathrm{s})\end{array}$ & $\begin{array}{l}\% \text { error in theoretical } \\
\text { estimate of } c_{L}\end{array}$ \\
\hline 1,1,1-trichloro-2,2,2-trifluoroethan & $\mathrm{C}_{2} \mathrm{Cl}_{3} \mathrm{~F}_{3}$ & 229 & 698 & 685 & $+2 \%$ \\
\hline $\begin{array}{l}\text { hexadecafluoroheptane } \\
\text { dichloropentafluoropropane }\end{array}$ & $\mathrm{C}_{7} \mathrm{~F}_{16}$ & 199 & 494 & 543 & -9 \\
\hline$(\mathrm{HCFC} \mathrm{ca} / \mathrm{cb})$ & $\mathrm{C}_{3} \mathrm{HCl}_{2} \mathrm{~F}_{5}$ & 151 & 648 & 650 & 0 \\
\hline 2-dichloropentafluoropropane & & & & & \\
\hline (HCFC-225 da) & $\mathrm{C}_{3} \mathrm{HCl}_{2} \mathrm{~F}_{5}$ & 124 & 672 & 638 & +5 \\
\hline 1-iodoheptafluoropropane & $\mathrm{C}_{3} \mathrm{~F}_{7} \mathrm{I}$ & 267 & 501 & 499 & 0 \\
\hline 2-iodoheptafluoropropane & $\mathrm{C}_{3} \mathrm{~F}_{7} \mathrm{I}$ & 251 & 535 & 499 & +7 \\
\hline 1-bromo-2-chloro-1,1,2-trifluoroethane & $\mathrm{C}_{2} \mathrm{HClBrF}_{3}$ & 132 & 736 & 672 & +10 \\
\hline 2-bromo-2-chloro-1,1,1-trifluoroethane & $\mathrm{C}_{2} \mathrm{HClBrF}_{3}$ & 129 & 736 & 655 & +12 \\
\hline 2-iodo-1,1,1-trifluoroethane & $\mathrm{C}_{2} \mathrm{H}_{2} \mathrm{~F}_{3} \mathrm{I}$ & 177 & 639 & 654 & -2 \\
\hline \multicolumn{6}{|l|}{$\begin{array}{l}\text { Couplants used in previous } \\
\text { acoustic microscopy studies }\end{array}$} \\
\hline water $\left(\right.$ at $\left.28.5^{\circ} \mathrm{C}\right)[10]$ & $\mathrm{H}_{2} \mathrm{O}$ & 11 & & 1506 & \\
\hline $\mathrm{FC}-72$ & - & 190 & & 505 & \\
\hline ethyl-iodide & $\mathrm{C}_{2} \mathrm{H}_{5} \mathrm{I}$ & 33 & 874 & 844 & +4 \\
\hline methyl-iodide & $\mathrm{CH}_{3} \mathrm{I}$ & 47 & 826 & 824 & +0.2 \\
\hline DOW-200 & - & 46 & & 870 & \\
\hline methanol & $\mathrm{CH}_{3} \mathrm{OH}$ & 18 & & 1027 & \\
\hline
\end{tabular}

order of $10 \%$ were not uncommon for molecules containing the heavier halogens. To deal with these discrepancies, Schaffs suggested that values of the $Q_{i}$ parameter might not be fixed for each type of bond; in particular, it was recommended that $Q_{i}$ values for chlorine and bromine be dependent on the number of $\mathrm{Cl}$ or $\mathrm{Br}$ atoms immediately adjacent to a carbon atom (Table I). In our evaluation of $Q_{i}$ for fluorine, insufficient velocity data were available to pursue such a course, and only a single $Q_{i}$ value of 1.815 $\mathrm{cm}^{3}$ was obtained.

For the generation of Rayleigh waves on an epoxy surface through acoustic microscopy, the couplant's acoustic velocity should be less than $800 \mathrm{~m} / \mathrm{s}$, and preferably lower than $700 \mathrm{~m} / \mathrm{s}$. Despite its highly-desirable low attenuation characteristics, the velocity of Dow-200 is relatively high $(870 \mathrm{~m} / \mathrm{s})$, and its low density leads to a severe impedance mis-match at the sapphire-couplant interface. Ethyl-iodide and methyl-iodide both have good attenuation characteristics but relatively high acoustic velocities for our purposes ( 844 and $824 \mathrm{~m} / \mathrm{s}$, respectively), and methyl-iodide is difficult to work with safely. The refrigerant 2-dichloropentafluoropropane emerges as the couplant of choice in terms of a compromise between low values of $c_{L}$ and $\alpha(638 \mathrm{~m} / \mathrm{s}$, and $124 \mathrm{~dB} / \mathrm{mm}$, respectively).

Although these measurements were conducted at 250 $\mathrm{MHz}$, the attenuation factor at other frequencies may be estimated by assuming a linear variation with frequency squared. However, such a scheme is unlikely to be adequate for extrapolating the present data to the upper frequencies of 1-2 GHz at which acoustic microscopy may be used.

Fig. 4 presents an experimental $V(z)$ curve, produced at a frequency of $250 \mathrm{MHz}$ on a bulk sample of HYSOL epoxy EA 9346. The coupling fluid used for this measurement was 2-dichloropentafluoropropane. The shorter period of
$\Delta z=7.9 \mu \mathrm{m}$ in Fig. 4 leads to an estimate for the fluidloaded Rayleigh speed of $1.20 \mathrm{~mm} / \mu \mathrm{s}$. This corresponds closely to a calculated value of $1.20 \mathrm{~mm} / \mu \mathrm{s} \pm 2 \%$, based on densities of the fluid and epoxy plus bulk wave velocity measurements on the epoxy at $25 \mathrm{MHz}$. The longer period of $35 \mu \mathrm{m}$ in the same figure leads to an estimate for a wave propagation velocity of $2.44 \mathrm{~mm} / \mu \mathrm{s}$ in the epoxy. It is concluded that this velocity corresponds to the lateral compression wave, based on the proximity of this velocity to the bulk compression wave speed of $2.48 \mathrm{~mm} / \mu \mathrm{s}$ $\pm 1 \%$ measured at $25 \mathrm{MHz}$. In addition, one can see a very short-period, low amplitude signal superimposed on the unfiltered spectrum of Fig. $4 \mathrm{a}$. The short period is equal to half the wavelength of the $250 \mathrm{MHz}$ signal in the coupling fluid; this feature is produced primarily by the unwanted echoes from the rim of the lens cavity.

\section{Conclusions}

A method has been presented for estimating the compression wave velocities of organic fluids that are candidates for acoustic microscopy studies of low-speed materials. The method requires as inputs only molecular constants that are commonly available in chemical reference books, plus the parameters $A_{i}$ and $Q_{i}$ that characterize each type of bond within an organic molecule. Values for these parameters were determined for C-Fl bonds in this study, and added to the list of data previously compiled by Schaffs [6]. The theoretical work was followed by experimental measurements of acoustic velocity and attenuation on nine fluorine-containing compounds, leading to the identification of several good candidates for couplants. The best candidate for acoustic microscopy of epoxy surfaces was identified as 2-dichloropentafluoropropane 
$\left(\mathrm{C}_{3} \mathrm{HCl}_{2} \mathrm{~F}_{5}\right)$, with $c_{L}=638 \mathrm{~m} / \mathrm{s}$, and $\alpha=124 \mathrm{~dB} / \mathrm{mm}$ at $250 \mathrm{MHz}$. Methyl-iodide, ethyl-iodide and DOW-200 have superior attenuation characteristics, provided that their relatively high velocities can be accommodated.

\section{REFERENCES}

[1] G. C. Knollman, "Variation of shear modulus through the interfacial bond zone of an adhesive," Int. J. Adhesion and Adhesives, vol. 5, no. 3, pp. 137-141, July 1985 .

[2] A. J. Kinloch, Durability of Structural Adhesives, London: Elsevier Science Publishers, 1983, pp. 33-34.

[3] J. Cognard, "The metal/polymer interphase in adhesive joints," Int. J. Adhesion and Adhesives, vol. 11, no. 2, pp. 114-116, April 1991.

[4] O. Hahn and G. Koetting, "Stress-dependent failure mechanisms in the glue line of metal bonds and their influence on bond strength," Schweissen und Schneiden, vol. 36, H6, pp. E89-E91, 1984.

[5] A. Weissler, "Ultrasonic investigation of molecular properties of liquids. III. Linear polymethylsiloxanes," J. Am. Chem. Soc., vol. 71,1949 , pp. 93-95.

[6] W. Schaffs, Molecularakustik: Eine Einfuehrung in die Zusammenhänge Zwischen Ultraschall und Molekulstruktur in Fluessigkeiten und Gasen, Berlin: Springer-Verlag, 1963, pp. 243-265.

[7] D. Sette, "Dependence of Sound Velocity on the Chemical and Structural Nature of the Liquids," in Handbuch der Physik, S. Flugge, Ed. Berlin: Springer-Verlag, 1961, vol. 11, Part 1, pp. $339-346$.

[8] K. Altenberg, "Ultraschallgeschwindigkeit und Molekülstruktur," Z. Phys. Chem., vol. 195, 1950, p. 145 .

[9] J. Attal and C. F. Quate, "Investigation of some low ultrasonic absorption liquids," J. Acoust. Soc. Am., vol. 59, no. 1, Jan. 1976 , pp. 69-73.

[10] A. Briggs, Acoustic Microscopy, Oxford Publications, 1992, pp. $30-32$.

[11] M. Greenspan, "Acoustic Properties of Liquids," in American Institute of Physics Handbook, New York: McGraw-Hill, 1963, p. 3-76.

[12] W. P. Mason, Piezoelectric Crystals and their Application to Ultrasonics. Princeton: Van Nostrand, 1962, p. 337.

[13] Smithsonian Physical Tables, W. E. Forsythe, Ed. Washington: Smithsonian Instiution, 1954, p. 307.

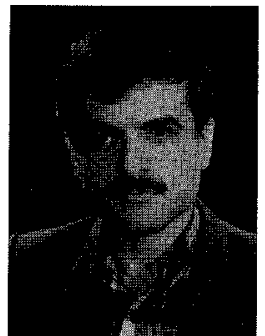

Vahid Safavi Ardebili was born in Varamin, TEH, Iran on December 31, 1961. He received the B.Sc. degree in mechanical engineering from the Sharif University of Technology, Tehran, Iran, in 1986, and the M.Sc. degree in mechanical engineering from the Sharif University of Technology in 1989. He is presently a Ph.D. student with the Department of Mechanical Engineering at the University of Toronto, Ontario, Canada, where he is working on adhesive interphase characterization and acoustic microscopy of plastics.

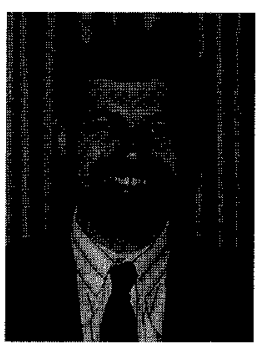

Tony Sinclair (M'89) received a Bachelor's degree in Engineering Science from the University of Toronto in 1976, and a M.Eng. and Ph.D. in Nuclear Engineering from the University of Michigan in 1980. After three years in the Nuclear Generation Division of Ontario Hydro, he joined the University of Toronto where he is currently an Associate Professor in the Mechanical Engineering Department. His primary research focus is the application of ultrasonic nondestructive evaluation to industrial problems, with specific interests in mathematical modelling and signal processing.

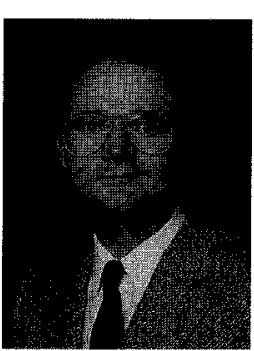

Jan K. Spelt is an Associate Professor in the Department of Mechanical Engineering at the University of Toronto. Prior to joining the University of Toronto in 1988, he worked for three years in the Kingston Research and Development Centre of Alcan International, Ltd. His research interests relate to adhesion and surface phenomena, and have led to publications in the design and testing of structural adhesive joints, biofouling, corrosion, and surface thermodynamics. 